\title{
Earthquake damage detection in Tehran's water distribution system
}

\author{
G. Badalians Gholikandi ${ }^{1}$, R. Rasti Ardakani $^{2}$, M. A. Pourjafari ${ }^{3}$ \\ \& R. Riahi ${ }^{1}$ \\ ${ }^{I}$ Power and Water University of Technology (PWUT), \\ Water Research Institute (WRI), Water and Wastewater Research Centre, \\ Tehran, Iran \\ ${ }^{2}$ Power and Water University of Technology (PWUT), \\ Water engineering faculty, Tehran, Iran \\ ${ }^{3}$ Guilan Water and Wastewater Company (GWWC), Rasht, Iran
}

\begin{abstract}
Iran is located in the one of world's large seismicity zones called ALPA (AlpHimalaya) and the mega city Tehran has is in a particularly dangerous situation. In a destructive earthquake, considerable damage occurs in buried structures such as the urban water supply system. In this study, the following objects are investigated: review of the damage analysis and seismic design of the water networks, review of the seismic information for water distribution systems, earthquake damage detection in water distribution systems, using an artificial neural network (ANN) and a general back error propagating perception to detect pipelines damaged due to earthquakes. The failure points are obtained by using the amount of water discharged from the tanks. The states probable failures have to be computed, the mathematical model for different states of pipe failure by which the damaged pipes could be detected through a back analysis. Since there are various types of failure, therefore, the ANN has been applied. Through a parametric study, different geometry, shape diameters and pressure of the water network are surveyed and the best network architecture for each case is obtained. The peak responses and phase delays are assumed to be network outputs. The network is trained in a supervised manner. The study shows the efficiency and capability of the ANN for modelling the observed nonlinear behaviour.
\end{abstract}

Keywords: earthquake, damage detection, water distribution, Tehran. 


\section{Introduction}

Iran is located in the one of world's large seismicity zones called ALPA (AlpHimalaya) and from time to time destructive earthquakes ensues in this country. Most of the cities are exposed to earthquake risk. The mega city Tehran is in a particularly dangerous situation. In a destructive earthquake considerable damage occurs in buried structures such as the urban water supply system.

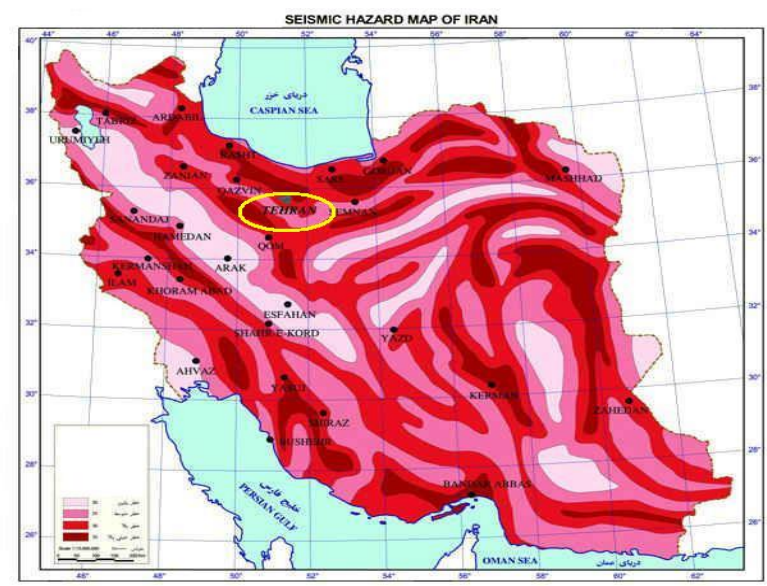

Figure 1: $\quad$ Seismic hazard map of Iran (International earthquake research centre [8]).

For seismic design, two different magnitudes of intensity are employed (JWWA [5]): Seismic Motion Level 1, which has a return probability of once or twice in the service life of the facility, and Level 2, which has a smaller probability than the former, but is greater in magnitude. Seismic Motion Level 1 (LI) is equivalent to the conventional seismic motion level set by many civil engineering construction guidelines. Seismic Motion Level 1 may be generated once or twice during the in service period of a structure. Seismic Motion Level 2 (L2) is the equivalent of the seismic motion generated in areas with faults or areas with large scale plates bordering inland areas. The probability of a water works system experiencing Seismic Motion Level 2 is very low. Nevertheless, the influence of a Seismic Motion Level 2 is considered enormously great. For planning seismic design, the water facilities are categorized into two: (1) facilities with a high level of importance (Rank A), (2) other facilities (Rank B).

The 1994 Northridge, the 1995 Kobe, the 1999 Turkey (Kocaeli) and Taiwan (Ji-Ji) earthquakes have shown that a moderate to strong earthquake in an urban environment with a population over one million people can cause water pipelines to be damaged in multiple thousands locations. There are two general approaches to examining pipeline damage under earthquake loading: the empirical approach and the analytical approach. 
Table 1: $\quad$ Seismic motion level and importance ranking (JWWA [5]).

\begin{tabular}{|l|l|l|l|}
\hline \multicolumn{1}{|c|}{ Seismic motion level } & \multicolumn{1}{|c|}{ Level 1 } & \multicolumn{1}{c|}{ Level 2 } \\
\hline & Rank A & No damage & $\begin{array}{l}\text { No severe impact on } \\
\text { human life Individual } \\
\text { facility may receive } \\
\text { Slight damage, but will } \\
\text { rank }\end{array}$ \\
\cline { 2 - 4 } & Rank B & $\begin{array}{l}\text { Individual facility may } \\
\text { receive slight damage } \\
\text { and may not be able to } \\
\text { function. Early } \\
\text { restoration possible. }\end{array}$ & $\begin{array}{l}\text { Individual facility may } \\
\text { receive some damage. } \\
\text { The water works system } \\
\text { retain its total ability to } \\
\text { function }\end{array}$ \\
\hline
\end{tabular}

\section{Influencing factor on pipes behaviour during earthquake}

Since the buried pipes are installed in the ground surface, the seismic behaviour of the pipeline is affected by the surrounding soil. These influencing factors are site ground characteristics, earthquake characteristics and pipe structure conditions. Generally, damage due to earthquakes in steady and uniform ground are less than other types. Topography, the ground water table, the thickness and the strength of soil layers are effective on ground response. The following factors decrease the steadiness of the ground: landslide potential, liquefaction and floating ability, slope, man made embankment land, soft layers and variation of the soil condition between the location of the pipeline and facilities. The intensity of the earthquake, the time histories of accelerations of horizontal and vertical waves, the duration, the peak ground acceleration (PGA), the peak ground velocity (PGV) and the amplitude are earthquake characteristics that affect seismic pipe behaviour.

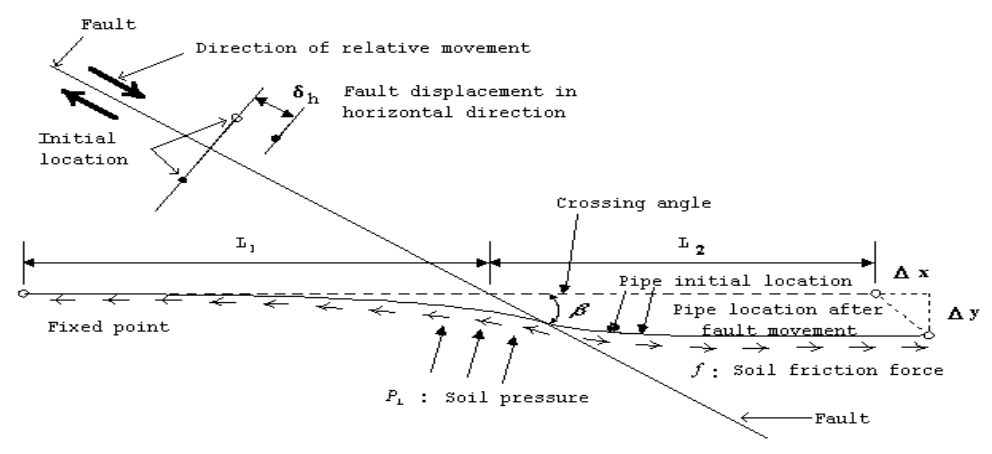

Figure 2: The analytical model for fault crossing pipe analysis neglecting section deformation (AWWA [2]). 


\section{Damage classification}

a) Pipe body damage: Three types of damage are exerted on pipe bodies. These are cracking, separation and buckling. (b) Joint damage: There is also damage reported for joints in past earthquakes. Most joint damage occurred in places in which the stiffness is changed. Cracking, joint failure, pullout separation, mechanical fracturing and leakage are damage modes of joints. (c) Fitting damage: Damage in fittings is related to the characteristics of facilities and the soils around them. Variable rigidity on the pipe route also has an affect on fitting damage. (d) Operation damage: Damage reported in past earthquakes is as follows: large leaks and reduction of water storage, flow of sand and soil in the pipes and water cut off, decreased water head pressure, difficulties for fire fighting, water cut off to a large area, some facilities are out of service due to electrical damage.

\section{Artificial neural network (ANN)}

A neural network is an information-processing unit originally intended to simulate the performance and characteristics of the human brain. The neural network is a computational technique that is able to learn characteristics of the introduced data and develop a generalization property. From a mathematical point of view, an ANN is vector transformation. Artificial neural networks are often named as black boxes. This is due to the fact that their functions are rarely evaluated. The ANN can be useful for complicated engineering problems. The ANN consists primarily of three basic elements: neurons, the architecture of the network and a learning rule $[3,4,6]$.

\subsection{Analysis of water distribution system}

\subsubsection{Direct analysis}

The effects of pipe damage on hydraulic parameters (i.e. pressure, velocity and discharge) are divided into two categories. The first case is related to the damage that results in water leakage, but water flow is not interrupted. The second case is related to the damage that leads to the escape of water and causes the water flow to be disconnected. In all the water supply networks during normal times there is still some leakage, so we consider that to be a leakage as high as 0.2 cubic meters per hour for each kilometre of pipe length (AWWA [2]). The rate of leakage when an earthquake happens suddenly increases. Leakage discharge is calculated by the Orifice rule (Streeter and Wylie [7]) as equation number (1).

$$
Q_{i}=K_{i}\left(P_{i}-P_{o}\right)^{n}
$$

where $Q_{i}=$ leakage discharge $\left(\mathrm{m}^{3} / \mathrm{s}\right), K_{i}=$ the constant coefficient with respect to shape and hole diameter, $P_{i}, P_{o}=$ the upstream and downstream head pressure of the hole (meter) and $n=0.5$.

Since the pressure in the downstream is always equal to zero, the equation above changes as follows: 


$$
Q_{i}=K_{i} P_{i}^{n}
$$

The discharge of outlet flow caused by the breakage and segregation of pipes and head loses energy in each pipe can be obtained from equations (3) and (4) (Streeter and Wylie [7]):

$$
\begin{array}{r}
Q=A_{e} \cdot V_{e} \\
h_{l}=\frac{f \cdot L}{D} \cdot \frac{V^{2}}{2 g}
\end{array}
$$

where:

$A_{e}$ is the effective area and $V_{e}$ is the effective velocity of water,

$f=$ the friction factor, $L=$ the length of the pipe (m), $D=$ the diameter of the pipe $(\mathrm{m})$,

$V=$ the flow velocity $(\mathrm{m} / \mathrm{s}), \mathrm{g}=$ gravity acceleration $\left(\mathrm{m} / \mathrm{s}^{2}\right)$,

$h_{l}=$ head lose in the pipe with length $L(\mathrm{~m})$.

Equation (4) can be rearranged in term of discharge as:

$$
h_{l}=\frac{16 f L}{2 g \cdot \pi^{2} \cdot D^{5}} Q^{2}=K \cdot Q^{2}
$$

where $K$ is a constant number for each pipe with known length, diameter and material. The head loses in each loop are obtained from equation (6):

$$
\sum K_{i j} \cdot Q_{i j}^{2}=0
$$

in which $i$ and $j$ are node numbers at the ends of pipes.

The flow entering a node must be equal to the flow emanating from it, including the water demand equation (7). Since the network considered is a closed system, the summation of flow entering or emanating from the network is zero.

$$
\sum Q_{i}=F_{i}
$$

where $F_{i}$ is the given output or demand at node $i$ and the summation takes place over all the pipes that connect to node $i$ with discharge of $Q_{i}$. At the end, combining equations (6) and (7), the system equations are written as follow:

$$
[k] \cdot[Q]=[F]
$$

$[K]=n \times n$ matrix where $n$ shows the number of pipes in the network, $[Q]=\mathrm{n} \times 1$ matrix, which indicates the discharge in the pipes and $[F]=$ the output discharge from the nodes.

To detect damaged pipes, the amount of $[Q]$ can be measured by installing a flow meter in branches; the amount of $[F]$ can be obtained by the difference of $[Q]$ in the joints. Now, by knowing $[Q]$ and $[F]$, and by using linear algebra and the optimizing method, the result is accountable. Since the initial $[K]$ is known, if the obtained $[K]$ is different, this shows where movement has happened and changes in $[K]$ detect the pipe damage. The mentioned method is not efficient because: 
Measuring $Q$ in each pipe is complicated.

$[K]$ is a $n \times n$ matrix, whereby using the linear algebra method, the answers would not be accurate.

This method is valid until the damage is so great that there are leakages and no segregation happens.

\subsubsection{Back analysis}

In this analysis the broken point is modelled as an imaginary tank with the topographic height of ground. The input discharge into an imaginary tank, which has become the same outlet discharge of the broken point, is calculated. For various cases the breakage of several imaginary tanks is considered and a database table is made. By applying this table in back analysis, damage detection is estimated. The recorded data in a water network for monitoring and controlling the water flow are mainly input for back analysis. Therefore it is highly recommended to find the most logical and scientific method for damage detection. Big cities have large networks including several pipes. Each network is composed of independent sub-networks. Each sub-network is supplied by two or more reservoir tanks. Several states of pipe damage may be identified in the network. By using an ANN, having some of the input data, the rest can be estimated. In this study, the back propagation network (BPN) was applied and a computer program was written in Fortran Power Station in an ANN environment. The following conditions are required to run the ANN computer program: input and output data are obtaining from the direct solution of the network and empirical data obtained from past earthquakes in the water supply system worldwide. These input and output data are only defined for a specific water network, consequently they cannot be generalized.

Table 2: $\quad$ Diameter and length of pipe in network.

\begin{tabular}{|l|l|l|}
\hline No. of pipes & Diameter $(\mathrm{mm})$ & Length $(\mathrm{Km})$ \\
\hline 1 & 400 & 2.050 \\
\hline 2 & 250 & 3.10 \\
\hline 3 & 400 & 2.90 \\
\hline 4 & 250 & 2.2 \\
\hline 5 & 250 & 2.42 \\
\hline 6 & 250 & 1.30 \\
\hline 7 & 250 & 2.8 \\
\hline 8 & 250 & 1.65 \\
\hline 9 & 250 & 1.8 \\
\hline 10 & 400 & 3.1 \\
\hline 11 & 250 & 2.4 \\
\hline 12 & 400 & 3.65 \\
\hline
\end{tabular}

\subsubsection{Case study}

A sub-network of the Tehran water supply system in the south-east of this city is considered with the following characteristics (figure 3). Several states of pipe 
damage exist in this network. The sub-net is analyzed by 200 different states to compute the outlet discharge values from tanks A and B. Since there are some observed outlet discharge values resulting from accidents in this sub-net in the past, the so-called computed data are adjusted by the observed data. Hence, the ANN technique was applied with back analysis to detect the damaged pipes (number of tanks: 2, head of tanks: 55 m, number of pipes: 12, number of loops: 4). In order to perform the adaptive ascending algorithm, the parameters shown in table 3 were applied to the program. The networks with 12 hidden neurons were converged. So, efficiency analysis and the final network architecture have been shown in figures 4-6 respectively.

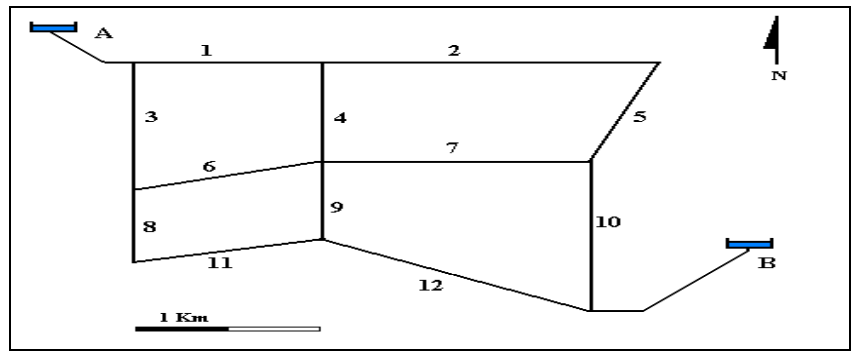

Figure 3: A sub-network of the Tehran water supply.

Table 3: $\quad$ Assumed network parameters in the case study.

\begin{tabular}{|l|l|}
\hline Parameter & Value \\
\hline Number of input neurons & 2 \\
\hline Number of output neurons & 12 \\
\hline Number of hidden layers & 1 \\
\hline Number of hidden neurons & 12 \\
\hline Activation function & Sigmoid \\
\hline
\end{tabular}

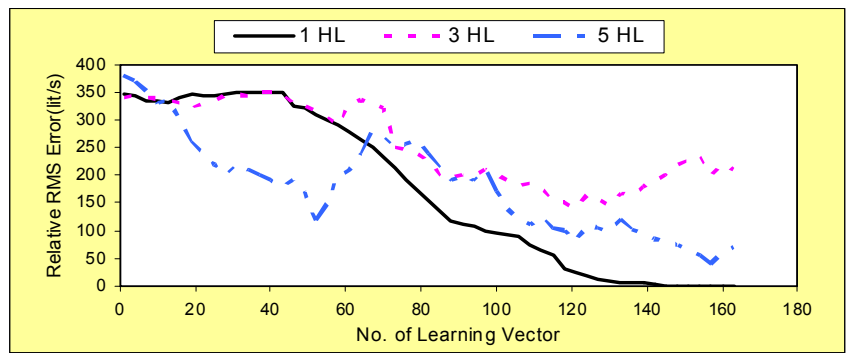

Figure 4: $\quad$ Network error for different numbers of hidden layers. 


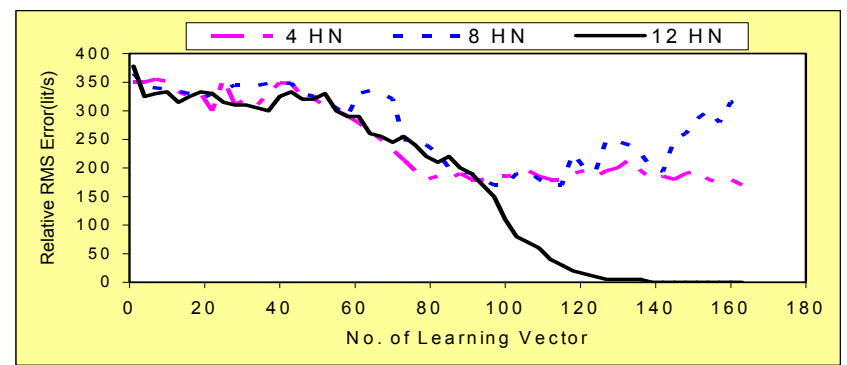

Figure 5: $\quad$ Network error for different numbers of hidden layer neurons.

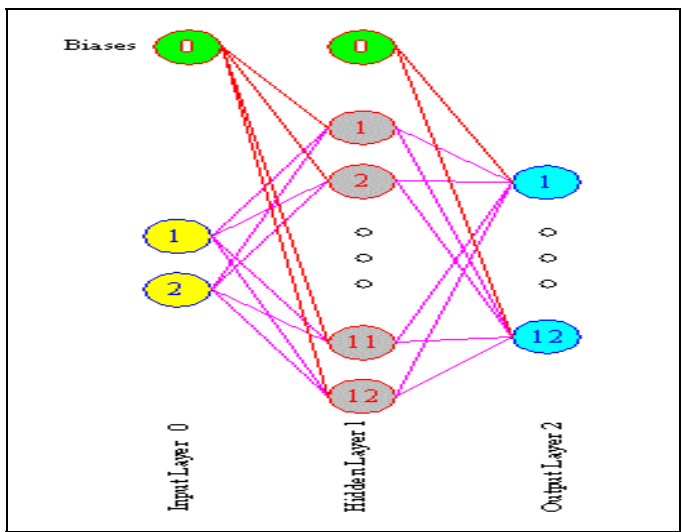

Figure 6: Final network architecture purposed for the problem.

\section{Conclusion}

Past earthquakes have shown that a moderate to strong earthquake in an urban environment with a population of over one million people can cause water pipelines to be damaged in thousands of multiple locations. The ground displacements (large and permanent ones) are more severe compared to ground shaking. The weakest points of the system against ground shaking are joints (screw and mechanical). From the results presented in this study it is concluded that the neural networks show great promise in becoming useful tools in practical analysis applications, especially for problems with severe nonlinearities. The ANN program written by this method is applicable for damage detection in all kinds of water supply networks. The generated database depends on geometric shape, type, the number of pipes and the characteristics of the pipes and tanks, which is calculated by direct analysis. It is more realistic if the observed data can be obtained from earthquakes that have taken place in the past. To increase the efficiency and obtain better results, the input neurons should be raised. These inputs can be the outlet discharge from other tanks or the pressure in several main nodes. 


\section{Acknowledgement}

This study was supported by the Guilan Water and Wastewater Company (GWWC), Rasht, Iran.

\section{References}

[1] Ash, T. (1989). Dynamic node creation in back propagation Networks, ICS Report 8901, UCSD Inst. for cognitive sciences.

[2] American Water Works Association, (1994). Minimizing earth-quake damage, A Guide for Water Utilities.

[3] Bishop, C.M. (1995). Neural networks for pattern recognition. Oxford University Press.

[4] Dayhoff, J.E. (1990). Neural network architectures. Van Nostrand Reinhold Press.

[5] Japan Water Works Association, (1979). Seismic Design and Construction Guidelines for Water Supply Facilities.

[6] Masri, S.F., Smyth, A.W., Chassiakos, A.G., Caughey, T.K. and Hunter, N.F. (2000). Application of neural networks for detection of changes in nonlinear systems. J. ASCE, Vol. 126, No. 7.

[7] Streeter, L.V. and Wylie, E.B. (1981). Fluid mechanics. McGraw Hill, $7^{\text {th }}$ Edition.

[8] International Earthquake Research Centre, http://www.iiees.ac.ir/, 2008. 